\title{
Symmetry - Collision of Arts and Sciences for a New Dimension
}

\author{
对称 一 艺术与科学碰撞的新维度 \\ Tony Yu Zhou ${ }^{1}$, Jenny Wen-xi Zhou'2, Ruben Van Leer ${ }^{3}$, \\ Chen Yang ${ }^{4}$ and Fritjof Capra ${ }^{5}$ \\ ${ }^{1}$ Inspirees Institute, China/The Netherlands \\ ${ }^{2}$ Beijing AWZ, China \\ ${ }^{3}$ Van Leer Film, The Netherlands \\ ${ }^{4}$ Shanghai Maritime Technology University, China \\ ${ }^{5}$ The Council of Earth Charter International
}

\begin{abstract}
A dialogue concerning the arts and sciences was prompted among the panelists of an international webinar in November 2020, which featured Symmetry - a dance-opera film shot inside CERN, the largest experimental particle physics facility in the world. With the cathedral-like majesty of the Large Hadron Collider as his theater, a modern physicist searches for the smallest primordial particle and discovers a love without end. The panelists, which included the film's writer and director, Ruben Van Leer, as well as other art directors, a dance choreographer, biomedical scientist, and art educator, shared their reflections from different perspectives on how the collision of arts and sciences can help us explore and expand a new dimension for a better understanding of human beings and nature, and the relationship between the two. The article ends with "A Systems View" of the living systems and art of Fritjof Capra, which reinforces the perspective of human-nature integration.
\end{abstract}

Keywords: Symmetry, dance-opera, arts and sciences, human beings and nature, Systems View

\section{摘要}

2020年11月的一次国际在线研讨会引发了客座嘉宾针对艺术与科学之间的对话。 该研讨会的主题是"对称"一部在欧洲核子研究中心 (CERN) 一世界上最大的实验性粒 子物理学设施内拍摄的舞蹈歌剧电影。以大型强子对撞机的大教堂般的威严为舞台，一 位现代物理学家寻找最小的原始粒子，并发现了一段没有尽头的爱情。包括电影制作人 及导演 Ruben Van Leer在内的艺术总监、舞蹈编导、生物医学家、艺术教育者等嘉宾成员 从不同的角度分享了他们的思考，探讨了艺术与科学的碰撞如何帮助我们探索和拓展一 个新的维度，更好地理解人类与自然，以及他们之间的关系。文章最后以著名物理学家 Fritjof Capra 教授关于生命系统的 "系统观” 结束，强调了天人合一的观点。

关键词: 对称, 歌舞剧, 艺术与科学, 人类与自然, 生命系统观 


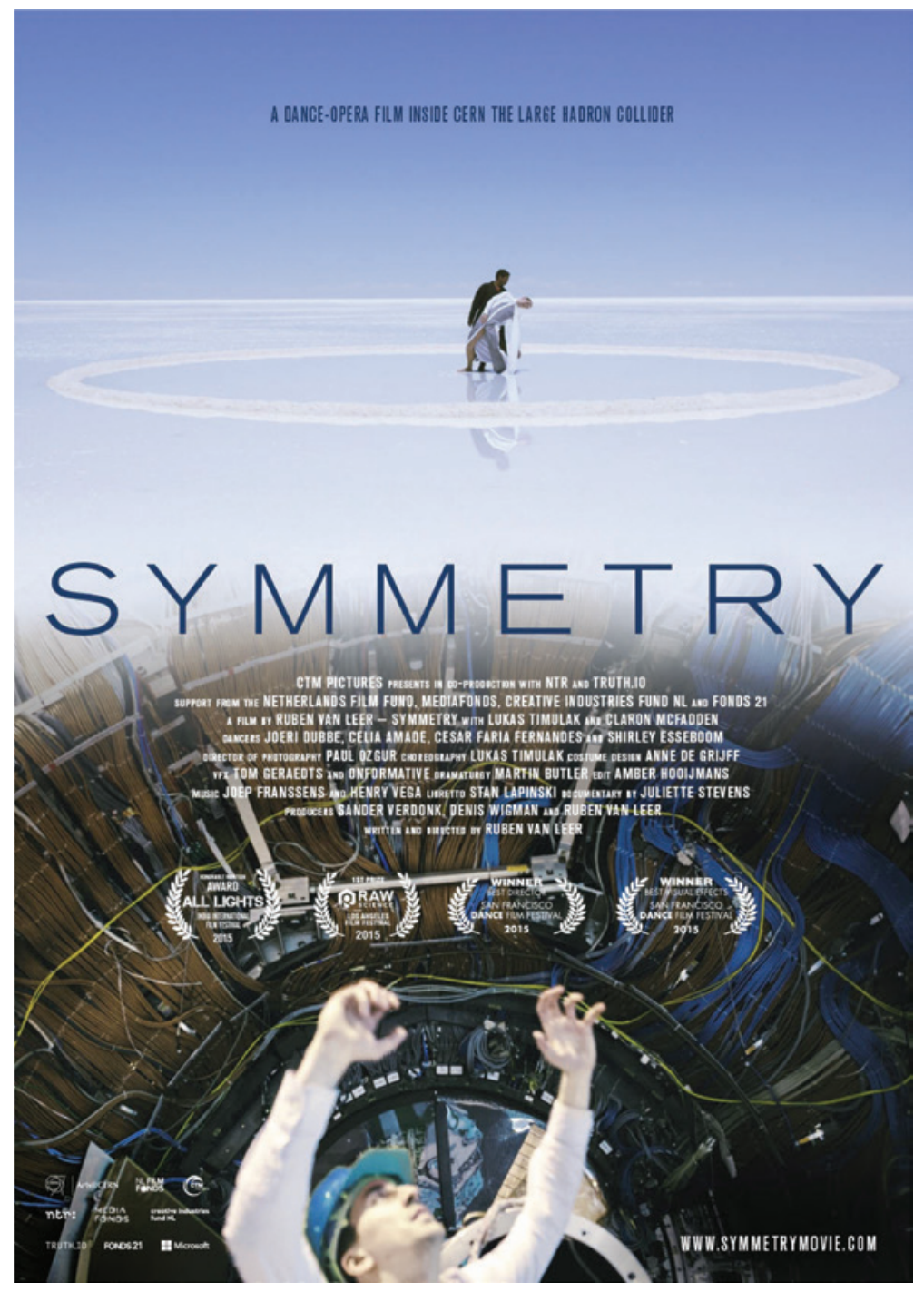

Introduction

\section{Zhou Jenny}

In 2015, a masterpiece of art and science was born in Europe. It is the dance-opera film Symmetry, and it was created by the well-known young Dutch filmmaker Ruben Van Leer. Symmetry spearheads the exploration of the intersection between art and science. The entire film was shot inside the Large Hadron Collider (LHC) at CERN, Switzerland. Thus, with the world's largest nuclear experimental facility as its backdrop, the work of artists and scientists comes together, blending soul and technology. The film consists of two parts: the first is a dance-opera movie, and the second is a behind-the-scenes documentary revealing the production process. The whole film is 53 minutes and 31 seconds long. 

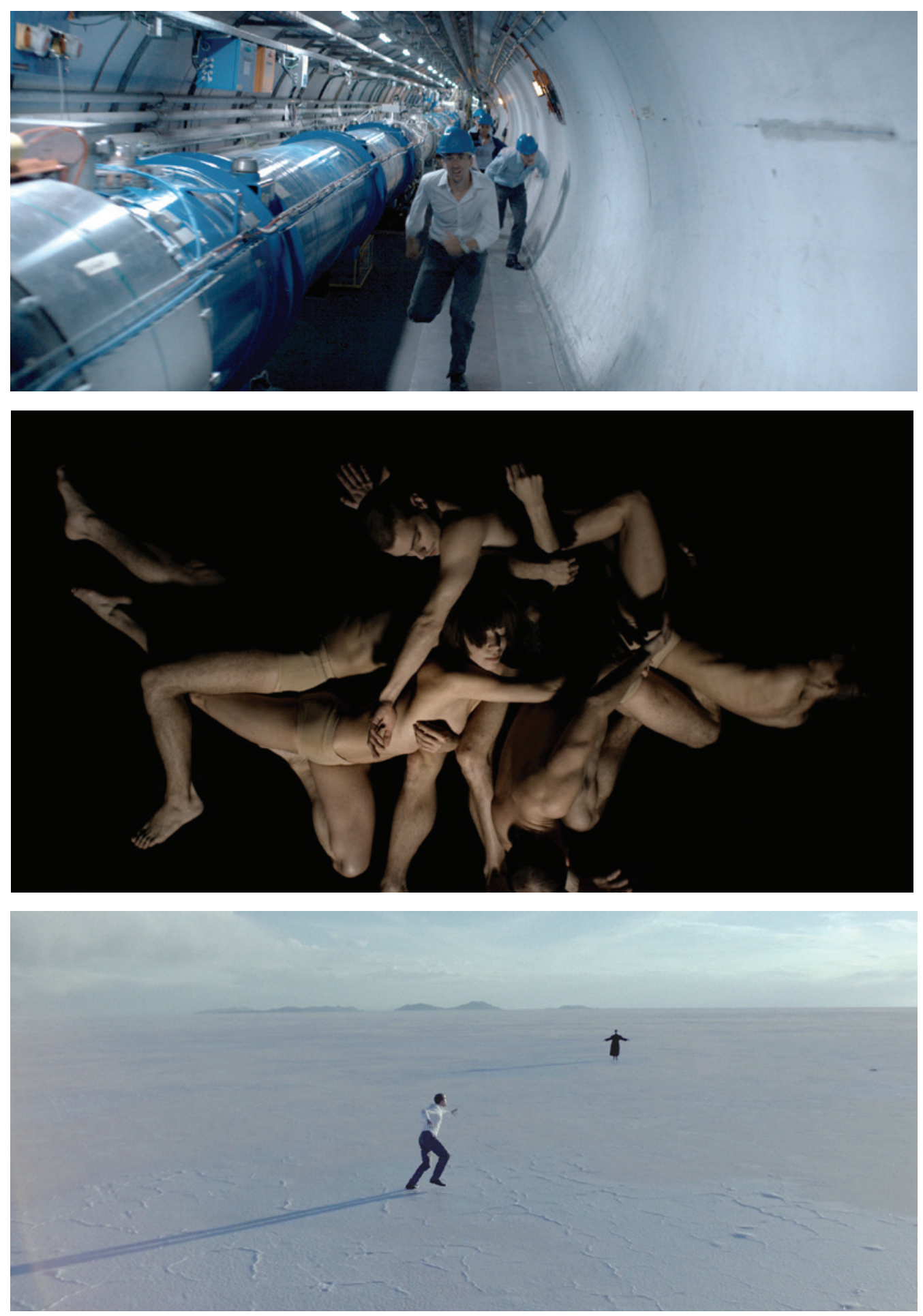

Film stills Symmetry. 
Symmetry tells the story of a physicist named Lucas who works at CERN and who has encountered difficulties while exploring the nature of the universe through the study of particles. After being summoned by Claron (McFadden), the God of Art, Lucas experiences a moment of enlightenment and as a consequence - being driven by love and seeing himself as part of the universe-leads his scientific team to explore and discover the true meaning of science and of man's relationship to himself and the universe. This exploration not only reveals the love between people and their inner souls, but also emphasizes the interdependence that exists between people and the inseparable state. From a philosophical standpoint, it also endeavors to explain the nature of people as well as their relationship to society, to the past, and to the present. The future is the meaning of the endless stream and the long-lasting flow in the universe.

The choice of characters is quite ingenious. The male protagonist, physicist Lucas, represents the scientific world and its onus to explore the meaning of life through science and technology; the God of Art, Claron, represents art and love and how these are used to explore the meaning of life through life itself. Thus, with art bringing the call of life and love, and science providing the requisite technology, the essence of life can be discovered.

The choice of CERN's LHC as the backdrop for the film is indicative of a certain Dutch artistic flair. The huge test site, with its intricate large-scale machinery and equipment, is a striking manifestation of the pursuit of the most pure and essential spiritual beauty. In the film, Princeton University physicist Robbert Dijkraaf says: "(CERN) is like a beautiful sculpture surrounded by a huge scaffold for me. Scientists and artists are there to explore the beauty of this simple essence. The 'same presence' is the touch of science and art that the film brings to us."

Particles studied by physicists are invisible to the naked eye. Like the world that artists feel, it is often impossible to express in words this microscopic world. However, in the fusion of science and art, when particles meet the small self, a magical collision occurs, and a remarkable thing begins to happen-human emotions are injected into science and scientific logic. By injecting art, we encounter empathy; empathy brings resonance. Resonance brings co-existence, and co-existence brings co-creation. Science is the foundation of art at your fingertips, and art is the presentation of scientific exploration via the imagination!

\section{The Making of Symmetry}

\section{Ruben Van Leer}

Perhaps the important aspect of the beautiful in a work of art lies in the active choice of its creator to enter into and illuminate the unknown. I think our project Symmetry, which I was able to film with choreographer Lukas Timulak, soprano Claron McFadden, and our crew inside the CERN particle accelerator, is an example of a work that is greater than our common denominator. It is for this reason that the artwork resonates with very different groups around the world. The title of the movie "Symmetry" alone has many 
connotations. In physics it refers to a transformation of an object while leaving the object itself unchanged. In Eastern philosophy, symmetry can refer to the primal symbols of the I Ching. And in art it represents harmony and beauty. The idea of symmetry can also have a negative connotation, as it can depict harsh forms of power and domination in a European national-socialist context. And a prominent scientific institute like CERN also provokes resistance among many conservative religious people, which became apparent shortly after the release of the film. In short, different interpretations of our project show that the film can be a mirror for a diverse international audience and a starting point for a larger, layered conversation.

Personally, the work has transcended me. During its first public screening at a cinema in Amsterdam, I read new layers of meaning into the film. While observing the final scene, in which Lukas and Claron depict an infinite movement of the yin and yang according to my script, I saw for the first time the figure of Jesus in Mary's womb (as in Michelangelo's Pietà). This transported me back to the memory that was the seed from which the entire project sprang: namely, my mother's unexpected death when I was 19. I suddenly understood that my underlying emotion for creating this project could have stemmed from a desire to reunite with my mother. I also saw Claron McFadden, who portrays the moment before the Big Bang in the story, as an ideal woman, with her outspoken artistic power, to whom my mother would have aspired.

At around the time when my mother died, when I had just started studying at art school, I read the controversial book The Tao of Physics, by physicist Fritjof Capra. CERN was mentioned: the largest scientific laboratory in the world, the place where the Big Bang is investigated at the quantum level, and where the internet was invented. Capra juxtaposed modern Western physics with Eastern mysticism and found parallels. The stories captured my imagination as a humble twenty-something. Much later when we released the film at the USA premiere in San Francisco, it was a great honour to meet with Fritjof Capra at the cinema show, who has been lecturing at Berkeley University nearby the venue. I associated the dancing body with the science of matter. I wrote Symmetry's film synopsis as a monomyth: a story about a scientist looking for the Theory of Everything who falls into the machine and finds himself at the moment before the Big Bang, where he is then tested by his conscience, and where he finally arrives at a holistic understanding of the cosmos... while dancing...I got the idea to link real CERN data with choreographic animations in the film (seen in the climax), to bridge at a glance the standard model in physics and modern physicssomething science is looking for today.

By coincidence, at around the same time as my studies, art curator Ariane Koek opened a Cultural Board within CERN, inviting international artists to create new work in collaboration with CERN scientists. I sent my synopsis with the film plan to an open call and was honored to have Symmetry not only accepted but to become the first project to be created at CERN. (More about their current projects can be found here: www.arts.cern) With a film plan and an invitation from the institute, I found a local film producer with whom I have started a regular financing process. After more than a year of much resistance from broadcasters, and trial and error with funds, we finally got the production off the ground and were able to enter the CERN site with our artist collective. 
What strikes one when arriving at the laboratory in Geneva is a statue of Shiva Nataraja, a deity from Hindu mythology. It depicts a cosmic dance as a metaphor for advanced research in the particle accelerator. We ended up having to shoot the entire film within three half-days. When we shot the scene where Lukas clashes with his fellow scientists, some of the physicists on the work floor spontaneously wanted to participate in the scene. These were all people who helped with the discovery of the Higgs boson (some call it the God particle) in 2012, right at that spot in CERN. In addition to the short but intensive adventure in CERN, I wanted to film on the mineral plain of Uyuni, to be able to depict that other dimension where our main character would end up. And so we flew to Bolivia with a mini-crew and the remains of our budget. Whereas at CERN we had been 60 meters underground amid overwhelmingly complex technology, here we now were more than 3,500 meters above sea level on a seemingly infinite plane in South America. At this magical location, each morning, an enormous water surface rises through the salt crystals of the floor. We see this miraculous reflection in the last scene of the film, bringing heaven and earth together in one image.

In the end, the media bosses were not very keen on broadcasting this artistic film project on public TV. I almost had to beg our local broadcaster in the Netherlands to screen the film. Finally, after months of waiting, we got an opening on TV, albeit with a lot of resistance from the organization. But the results were special: according to the TV figures, the film ended up with twice as many viewers as the average cultural program. We even received flowers from the broadcaster after the show, along with a thank you for having enticed so many viewers, in spite of their low expectations. In the end, we won 12 international awards with the work and the international press wrote about it. The point I want to make here is that the major media corporations, which are increasingly spreading our cultural stories today, have no intention of exploring independent artistic (dance) productions such as Symmetry. And they also seem unaware of an invisible but growing demand from a general audience for special programs with existential topics. In my opinion, this is a discrepancy that requires more attention than ever. I therefore hope that our film Symmetry and the conversations that the project triggers within, for example, the Chinese art education community, will encourage other artists, media makers, and multidisciplinary collaborations to share their own independent stories to a global audience!

\section{Art-Science-Revisiting Zhuangzi and Chinese Ancient Wisdom}

\section{Tony Yu Zhou}

I can remember the first time I watched Symmetry: it was 2015, and it was broadcast on the Dutch national TV channel. At the time, I could not foresee how the movie would stay in my mind and in my life for so long; but it has stirred, and continues to stir, my curiosity and interest in art and the universe to this day. With a simple yet sophisticated story, with direct yet profound images, sounds, and dances, the film brings us into a world where science and art, humans and the universe, are intertwined. I was fascinated by the mystery of this artistic piece, and by the dialogue that ensues between man and nature in the midst of an unusual dimension. Here, science and art are put on an equal 
footing, stimulating novel dialogue and interaction. As a result, we feel our smallness as human beings and the greatness of nature, and we are moved by the great aura of love that ultimately unites us with the universe.

Over the last six years, I have always shared Symmetry in my lectures and presentations in universities and conferences. Each time it is played, it never fails to move the audience and to trigger a diversity of feelings. These feelings vary widely and depend upon each person's perspectives and experiences and are thus deeply personal and intimate. Yet they resonate and connect us all on a common emotional and spiritual level because we are all members of one common human species. In a modern civilization dominated by highly developed science and technology, human individuals and societies have become increasingly rational and linear, and there is a great lack of artistic experience with a sense of flow and embodiment. What is more, even in the field of arts and humanities, we unconsciously use linear and quantitative tools and frameworks to define, interpret, and evaluate art, thus limiting the power of art as a messenger, which is itself a gift from nature. At this time, language, like science and technology, seems so pale and powerless. We feel there is a voice and life in our hearts that can only be expressed through authentic art flow. It is this desire and motivation that has driven me to stay with Symmetry and which eventually led me to decide to feature the movie in the CAET webinar series starting in 2018. Ruben Van Leer, the director of the film, was surprised by my "obsession" with his work, and he was both surprised and flattered by the fact that we brought together more than 80 Chinese professional colleagues for the webinar in 2020. In this lecture, the views and perspectives of the East and the West once again collided, mixed, and progressed through the known and the unknown. This flowering of ideas exactly fulfils our original intention of creating the CAET journal and webinars: to explore and discover ourselves and the universe in art — "Wu wei" - and the balance of "yin and yang."

Being trained in the Western scientific system, I had rarely imagined how art could contribute to the development of science and help scientific discovery. Science and art seem to be completely different fields, hardly intertwined. But in Symmetry we see how scientists can enter a new world through art and find inspiration for scientific experiments. Although this is ostensibly fiction and an artwork, no one can deny the certain reality behind these apparently mysterious phenomena. The second part of the film is a behindthe-scenes interview with several scientists at CERN, all of whom undoubtedly affirm the important role that art plays in scientific exploration. We all know that science has its limits, and that quantum entanglement and human psychological phenomena are difficult to fully explain using classical physics and neuroscience, owing to the fact that the human perspective and the scientific system represent only a small fraction of the universe. Looking back over the past few years, I realize that without the personal embodiment experience and practice in the field of art, it would not have been possible for me to appreciate and embrace art from a different perspective and incorporate it into an attempt to view life and the world in conjunction with science.

It is intriguing that, on the one hand, in the current field of art education and art therapy we try to validate art by science, and on the other hand, when we encounter bottlenecks in scientific discovery, we come to art to find inspiration. This seems to be 
a paradox. Perhaps we need to reflect on our current education system and the practice of science and art. Although the Renaissance liberated and empowered human beings, putting us at the center of the spotlight, the harmonious relationship between man and nature will be, indeed must be, the main thread that informs and guides the sustainable development of mankind. Modern art in the West focuses on personal expression, taking art as a personal statement, while the ancient East takes art as a way of personal cultivation and growth, exalting the interaction between man and nature and the unity of heaven and man. At this point, I cannot help but think of Zhuangzi's "A Happy Excursion" (逍遥游), which reads:

In the northern ocean there is a fish called the k'un (鲲). I do not know how many thousand li it measures in size. This k'un changes into a bird, called the p'eng. Its back is I do not know how many thousand li in breadth. When it moves, it flies - its wings obscuring the sky like clouds.

When on a voyage, this bird prepares to start for the Southern Ocean, the Celestial Lake. And in the Records of Marvels we read that when the p'eng (鹏) flies southwards, the water is smitten for a space of three thousand li around, while the bird itself mounts upon a great wind to a height of ninety thousand li ('half kilometer'), for a flight of six months' duration. (Translated by Lin Yu-tang)

Ancient Chinese wisdom has foretold the insignificance of man in nature, and Zhuangzi encouraged us not to see the world only from man's own perspective, but to step out of our own limited world and discover ourselves and the universe with a more macroscopic and far-reaching attitude. Watching Symmetry again, I felt like I had entered into the artistic scene of Zhuangzi - A Happy Excursion, truly becoming a tiny particle in nature, small but endowed with infinite power.

\section{Reflection and Resonance between East and West}

\section{Chen Yang}

The value of a good work of art is that it brings a variety of unique experiences to the various individuals who experience it, in the same way that a thousand readers have a thousand Hamlets. Heisenberg, a famous physicist, once pointed out that in observing the world we cannot be a purely objective observer without intervening and influencing the observed things. When appreciating a work, each of us will actually evaluate it from the perspective of our own knowledge and experience. When I watched Symmetry on the Internet, my first reaction did not concern the philosophical meaning of the film but the sense of ritual that permeated its strong sense of form. The music and singing throughout the work are impressive, with distinct rhythms and powerful penetration. The sound and melody of the singing are like a hymn between heaven and earth. That visually "naked" dance picture struck me emotionally with shock.

It reflects the highest realm of Chinese aesthetics, which states: "Make your voice with silence and your appearance invisible." It makes me believe that pure beauty can 
be plain and simple, too. It also confirms the truth of the "great simplicity" in Chinese philosophy.

Personally, I do not want to associate this Western artistic work about a scientific phenomenon with the Chinese Tai'Chi concept. Although there are many black and white symmetrical and circular scene designs in this work, I regard it as a natural artistic merge between Chinese and Western cultures and thoughts that eventually achieved the "same way" outcome. The connection and contrast between Chinese and Western cultural symbols are reflected incisively and vividly in the style of dancing and in particular how the upper body is held: the Chinese dancers' round and soft body bending and emphasis on the center of gravity contrast with the Western ballet dancers' stress on the upper body standing upright; but what they have in common is that both the center of the body and the power of movement come from the inner core of the pelvis.

I have always felt that, through our constant exploration and experience of the universe, these unknowns are always present regardless of the thousands of discoveries we have already made and regardless of the expansion of our cognition. We are actually using the constant exploration of the "unknown" field to confirm again and again "who we are, where we come from, where we go." Human civilization and history are developing and changing every day, but people in different regions tell interesting stories in their own ways. These stories share many similarities, with only small differences in forms. It is precisely because of these differences that they appear to be rich in interest between peoples. Just as a beam of light reflects multiple colors, Chinese and Western cultures are the two bright ones among these colorful bundles. As Heisenberg once put it: "In the history of the development of human thought, the most effective development occurs almost at the intersection of two different ideas, which may originate from very different parts of human cultures of different periods, and of different cultural environments or different religious traditions. Therefore, if its doors truly converge, that is, if they are at least connected to such a degree that real interaction occurs, then we can expect to follow them with novel and interesting developments."

\section{Living Systems Art and Design Collaboratory: A Systems View}

Fritjof Capra

\section{A New Conception of Life}

At the forefront of contemporary science, the universe is no longer seen as a machine composed of elementary building blocks. We have discovered that the material world, ultimately, is a network of inseparable patterns of relationships; that the planet as a whole is a living, self-regulating system. The view of the human body as a machine and of the mind as a separate entity is being replaced by one that sees not only the brain but also the immune system, the bodily tissues, and even each cell as a living, cognitive system. Evolution is no longer seen as a competitive struggle for existence but rather as a cooperative dance in which creativity and the constant emergence of novelty are the driving forces. And with the new emphasis on complexity, networks, nonlinearity, and patterns of organization, a new science of qualities is slowly emerging. 
"The systems view of life" integrates four dimensions of life: the biological, cognitive, social, and ecological dimensions. It requires a new kind of thinking thinking in terms of relationships, patterns, and context. In science this is known as systemic thinking, or "systems thinking." Thinking in terms of relationships is crucial for ecology, because ecology — derived from the Greek oikos ("household") — is the science of the relationships among various members of the Earth Household.

Systems thinking is not limited to science. Many indigenous cultures embody profound ecological awareness and think of nature in terms of relationships and patterns. Thinking in terms of patterns is also characteristic of the arts, and that artists therefore have an important role to play in propagating the systems view of life.

In modern science, systems thinking emerged in the 1920 s from a series of interdisciplinary dialogues among biologists, psychologists, and ecologists. In all these fields, the scientists realized that a living system - an organism, ecosystem, or social system - is an integrated whole whose properties cannot be reduced to those of smaller parts. The "systemic" properties are properties of the whole, which none of its parts have.

During the 1970s and 1980s, systems thinking was raised to a new level with the development of complexity theory, technically known as "nonlinear dynamics." It is a new mathematical language that allows scientists for the first time to handle the enormous complexity of living systems mathematically. Chaos theory and fractal geometry are important branches of complexity theory. The new nonlinear mathematics is a mathematics of patterns, of relationships. Strange attractors and fractals are examples of such patterns. They are visual representations of the system's complex dynamics. At the same time, these patterns can be very beautiful and, in fact, have often been used by artists.

During the last thirty years, the strong interest in nonlinear phenomena generated a whole series of new and powerful theories that have dramatically increased our understanding of many key characteristics of life. My synthesis of these theories is what I refer to as the systems view of life.

\section{Living Networks}

One of the most important insights of the systemic understanding of life is the recognition that networks are the basic pattern of organization of all living systems. Ecosystems are understood in terms of food webs (i.e., networks of organisms); organism are networks of cells, organs, and organ systems; and cells are networks of molecules. The network is a pattern that is common to all life. Wherever we see life, we see networks. Indeed, at the very heart of the change of paradigms from the mechanistic to the systemic view of life we find a fundamental change of metaphors: from seeing the world as a machine to understanding it as a network.

Closer examination of these living networks has shown that their key characteristic is that they are self-generating. In a cell, for example, all the biological structures - the proteins, enzymes, DNA, cell membranes, etc. - are continually produced, repaired, and regenerated by the cellular network. Similarly, at the level of a multicellular organism, the bodily cells are continually regenerated and recycled by the organism's 
metabolic network. Living networks continually regenerate themselves by transforming or replacing their components. In this way they undergo continual structural changes while preserving their web-like patterns of organization.

This coexistence of stability and change is indeed one of the key characteristics of life.

Life in the social realm can also be understood in terms of networks, but here we are not dealing with chemical reactions; we are dealing with communications.

Social networks, as you well know, are networks of communications. Like biological networks, they are self-generating, but what they generate is mostly nonmaterial. Each communication creates information, ideas, and meaning, which give rise to further communications, and thus the entire network generates itself.

\section{Systemic Problems - Systemic Solutions}

My synthesis of the systems view of life is not only theory but has very concrete applications. In the last part of our book, titled Sustaining the Web of Life, we discuss the critical importance of the systems view of life for dealing with the problems of our multifaceted global crisis.

Today, it is becoming more and more evident that the major problems of our time - energy, environment, climate change, economic inequality, and now the COVID pandemic - cannot be understood in isolation. They are systemic problems, which means that they are all interconnected and interdependent. They require corresponding systemic solutions - solutions that do not solve any problem in isolation but deal with it within the context of other related problems.

Over the last few decades, the research institutes and centers of learning of the global civil society have developed and tested hundreds of such systemic solutions all over the world. They include proposals to reshape economic globalization and restructure corporations; new forms of ownership that are not extractive but generative; a wide variety of systemic solutions to the interlinked problems of energy, food, poverty, and climate change; and finally, the large number of systemic design solutions known collectively as ecodesign, which embody the basic principles of ecology.

The new systemic understanding of life has given us the knowledge and the technologies to solve our major problems and build a sustainable future. What we need is political will and leadership.

\section{Systems Thinking and the Arts}

In conclusion, let me come back to the important role of artists in the current shift from the mechanistic to the systemic understanding of life. Systems thinking, as I have mentioned, involves a shift of perspective from the parts to the whole, from objects to relationships and patterns. Conventional science has concentrated on measuring, on quantities. But relationships cannot be measured and quantified; they need to be visualized and mapped. So there is also a shift from measuring to mapping, from quantities to qualities.

This is a very important aspect of studying patterns, and it is the reason why, throughout history, artists contributed significantly to the advancement of science by 
studying patterns. Perhaps the two most famous examples are Leonardo da Vinci, whose whole scientific life was a study of patterns, and the German poet Goethe in the 18th century, who made significant contributions to biology through his study of patterns.

My work in environmental education has convinced me that there is hardly anything more effective than the arts - the visual arts, music, or the performing arts - for developing and refining our natural ability to recognize and express patterns. Thus, the arts can be a powerful tool for teaching systems thinking, in addition to enhancing the emotional dimension that is essential to transformative learning.

As we recognize that our sciences and technologies have become increasingly narrow in their focus, unable to understand our multi-faceted problems from an interdisciplinary perspective and dominated by corporations more interested in financial rewards than in the well-being of humanity, we urgently need a science that honors and respects the unity of all life, recognizes the fundamental interdependence of all natural phenomena, and reconnects us with the living Earth. What we need today is exactly the kind of synthesis of science and art Leonardo da Vinci anticipated and outlined 500 years ago.

\section{About the Authors}

Tony $\mathrm{Y}$. Zhou, $\mathrm{PhD}$, is the Co-Founder and $\mathrm{CEO}$ of Inspirees Education Group. $\mathrm{He}$ is also the founder and executive editor of Creative Arts in Education and Therapy (CAET). He trained as a biomedical scientist and later received training in dance/ movement therapy and is the first certified movement analyst in mainland China. He cofounded the International Association of Creative Arts in Education and Therapy (IACAET) in 2019. He is the group leader of the Chinese Arts Therapy Committee under Chinese Psychological Society. ORCID:0000-0001-8099-6458. Email: t.zhou@ inspirees.com

Fritjof Capra, $\mathrm{PhD}$, physicist and systems theorist, was a founding director (1995-2020) of the Center for Ecoliteracy in Berkeley, California. He is a Fellow of Schumacher College (UK) and serves on the Council of Earth Charter International. Capra is the author of several international bestsellers, including The Tao of Physics, The Web of Life, and The Science of Leonardo. He is coauthor, with Pier Luigi Luisi, of the multidisciplinary textbook, The Systems View of Life.

Ruben Van Leer graduated from the Master Rietveld Academy Amsterdam in 2007 and got a second Master degree in Film at the Dutch Film Academy in 2013, after which he produced a wide variety of interdisciplinary projects like the space opera film shot inside CERN the large hadron collider Symmetry, the live music performance and VR installation Sacred Environment, the award winning short film The Boxer (commissioned by Dutch National Opera). He worked with a multi-disciplined arts community amongst which opera maker Michel van der Aa (interactive song cycle The Book of Sand), filmmaker Peter Greenaway (live installation Writing On Water), jazzist Tigran Hamasyan (music video Cave Of Rebirth) and choreographer Emio Greco (staging dance opera Non Solo Medea). 
Cheng Yang, director and associate professor of art education center of Shanghai Maritime University. Master degree from Shanghai Normal University Conservatory of Music dance education major. At present, she is also a special professor of Shanghai Zhenghe Research Center. She has published many papers on marine art and belief. She is the first scholar in domestic universities to study marine culture and belief from the perspective of dance art. At the same time, she is also the committee member of IACAET (International Association of Creative Arts in Education and Therapy) China committee, focusing on dance healing and ecological healing interaction and combination of further pioneering research and contribution.

Jenny Zhou obtained her master's degree in choreography from Beijing Dance Academy in 2017 and has been trained in Inspirees dance therapy program with American Dance Therapy Association Alternate Route. She has been working as a dance choreographer, art educator and director, dance therapist since 2006. 